\title{
An Analysis of Preference for Forest Therapy Programs Depending on the Emotional Characteristics of Subfertile Women
}

\author{
Seo-Yun $\mathrm{Bu}^{1}$ and Chang-Seob Shin ${ }^{2 *}$ \\ ${ }^{1}$ Graduate Department of Forest Therapy, Chungbuk National University, Cheongju 28644, Korea \\ ${ }^{2}$ Department of Forestry, Chungbuk National University, Cheongju 28644, Korea
}

\section{ABSTRACT}

This study aimed to analyze the preference of subfertile women for forest therapy programs depending on their emotional characteristics, and to provide basic data for the development of forest therapy programs in order to promote the mental health of subfertile women. Among the surveyed emotional characteristics of subfertile women, the level of emotions including pressure to become pregnant, impatience and frustration were high, while that of emotions including anxiety and fear; depression, hopelessness, helplessness, loneliness and sadness tended to be medium. The level of emotions including shame and guilt tended to be low. The top six forest therapy programs preferred by subfertile women include a deep breath of air /phytoncide, forest bathing/wind bathing/sun bathing, self-esteem recovery program, eating organic foods, low body bathing/foot bathing/hot spring bathing, and breathing/breathing exercises. Subfertile women highly pressured to become pregnant showed significant differences in the preference of the self-esteem recovery program, Domar 's relaxation therapy, NLP therapy, and sleeping in the woods, while women with anxiety and fear showed significant differences in the preference of walking barefoot in forests, mountain walking in silence, listening to water sounds/ hand and foot soak, self-esteem recovery program, NLP therapy, cognitive behavior therapy, aroma therapy, integrated art therapy in forests, forest bathing/wind bathing/sunbathing, a deep breath of air/phytoncide, and observing stars. Women with depression, hopelessness, helplessness, loneliness, and sadness showed significant differences in eating organic foods, self-esteem recovery program, counseling/coaching, and cognitive behavior therapy. The significance of this study was to analyze the preference of subfertile women, as subjects, for forest therapy program. The results of this study are expected to be used as basis data for developing forest therapy programs for subfertile women.

Keywords: depress, pregnancy rate, subfertile stress

\section{Introduction}

The total fertility rate in the Republic of Korea in 2018 was 0.98 , much below the total fertility rate required to maintain the current population (2.1) and the average total fertility rate of OECD countries (1.68; Lee, 2019). Worse yet, the number of those who were diagnosed with subfertility has continued to increase to at least 600,000 couples, resulting in a serious situation (Korea Institute for Health and Social Affairs [KIHASA], 2015). To address these issues, the Korean government introduced a program for supporting subfertile couples in 2006 as an effort to promote childbirth, and has continued to pay for expenses for assisted reproductive procedures. In addition, from July, 2019, procedures for subfertile couples that used to be non-covered items such as artificial insemination and external fertilization started to be covered by the National Health Service, and the number of those born to subfertile couples over the past five years reached over 100,000. In 2017, 20,854 babies were born to subfertile couples, accounting for about $5.8 \%$ of the total number of newborn babies in Korea in 2017. The World Health Organization

Received: August 27, 2019, Revised: September 6, 2019, Accepted: September 10, 2019

First author: Seo-Yun Bu, byh627@gmail.com, (D) https://orcid.org/0000-0003-0179-6808

*Corresponding author: Chang-Seob Shin, sinna@chungbuk.ac.kr, (10) https://orcid.org/0000-0002-6298-1487 
(WHO) defines infertility or sterility as the failure to achieve a clinical pregnancy after 12 months or more of regular unprotected sexual intercourse. The Korea Federation of Subfertility Family had carried on a national petition campaign since 2005, and contributed to the revision of the Mother and Child Health Act in 2016, replacing infertility with subfertility (Mother an Child Health Act, 2016). The term, subfertility, means a state of having difficulty in getting pregnant, and opens the possibility of childbearing.

Subfertile women, however, experience emotional difficulties from subfertility such as stress, depression and anxiety. Emotions are not only connected with humans' essential desire (Frijda, 1986), and are also known to have humans set their viewpoint toward themselves as well as others and to have a strong impact on interactions with others (Greenberg, 2004). It was also reported that the level of stress that subfertile women experience during the long and hard times of subfertility is similar to that of stress that cancer patients experience. Stress from subfertility was reported to reduce the rate of pregnancy, and repeated failures of pregnancy were found to increase stress from subfertility and depression, which again reduces the rate of pregnancy, causing a vicious circle (Domar et al., 1993). The extended subfertility makes subfertile women exhaust a substantial amount of energy and feel physical discomfort and even mental pain during repeated tests and treatments for subfertility (Kang, 2015). Subfertile women tend to avoid interpersonal relations and thus experience a sense of alienation and loneliness. At the same time, they tend to keep away from others who experience general childbirth in society, which makes them further isolated from society (Park, 2018). In particular, their unhealthy emotional state causes functional changes in the hypothalamic-pituitary-ovarian axis, which results in several negative effects such as menstrual irregularity by advancing or delaying ovulation (Ebbesen et al., 2009). It was also reported that $94.6 \%$ of subfertile women show mental pain and depressive symptoms from subfertility, which requires an urgent intervention in the emotional state of subfertile women (KIHASA, 2011). As an effort to address these issues, the Korean government has placed a professional counselor of subfertility in public health centers, and has provided a counseling service through subfertility clinics. However, the rate of utilization has been very low and issues such as lack of expertise in subfertility counseling have been pointed out (Ministry of Health and Welfare, 2016), which requires the development of more substantial measures.

Forests provide an ideal therapeutic natural environment as they reduce stress and improve immunity (An et al., 2010). A number of scholars pointed out that forests treat people's mental and physical diseases in modern society in a fundamental way by reducing stress (Adevi and Grahn, 2011; Alvarsson et al., 2010; Frumkin, 2001; Grahn and Stigsdotter, 2010; Gullone, 2000; Lottrup et al., 2013; Mitchell and Popham, 2008; Simaika and Samways, 2010; Ulrich, 1983). In addition, contact with nature gives benefits to individuals who experience depression (Gonzalez et al., 2009), and even looking at photos of nature provides several effects such as refreshing, controlling emotions and improving will power (Johnsen and Rydstedt, 2013), and reduced the level of cortisol, a stress hormone (Sung et al., 2012). Another study showed that the more people looked at green colors, the more resilient they were from stress (Lee, 2007).

Ha (2014) pointed out that forest therapy programs need to reflect the characteristics and needs of participants. The needs or preference of participants in forest therapy programs have been analyzed in several earlier studies including an analysis of needs for the development of forest therapy programs (Kim, 2015), an analysis of preference of general adults on forest therapy programs (Kim et al., 2014a), an analysis of needs for the development of forest therapy programs utilizing urban forests (Park, 2018), and an analysis of needs for forest therapy programs depending on the level of stress (Kim et al., 2014b). However, there is almost no study on forest therapy programs for subfertile women or those related to subfertility or the effects of forest therapy. Against this backdrop, this study aimed to conduct a survey on the preference of subfertile women who came to a subfertility clinic in Seoul for forest therapy programs depending on their emotional characteristics, and to provide basic data for the development of forest therapy programs in order to promote the mental and physical health of subfertile women based on the results of analysis. 


\section{Research Methods}

\section{Subjects and research methods}

In this study, questionnaire sheets were distributed to and collected from women who came to a subfertility clinic in Seoul on the spot using the convenience sampling method after directly informing them of the purpose of this study and obtaining their consent. The questionnaire survey was performed from January 21 to February 8, 2019. A total of 210 questionnaires were collected, but 200 were finally analyzed after excluding 10 questionnaires with incomplete information. Among the subfertile women who participated in the questionnaire survey, the number of those aged between 35 and 39 was the highest (79, 40\%), followed by those aged between 30 and 34 (58, 29\%), and those aged 40 or higher $(55,27.5 \%)$. The number of those who were married for less than one year was $9(4.5 \%)$, and those who were married for 3-5 years, 51 (51\%), and the number of those who were married for 5-10 years was the highest $(52,26.1 \%)$. The number of those who were diagnosed with subfertility after being married for 1-2 years was the highest $(67,34.4 \%)$, followed by within one year $(40,19.5 \%), 2-3$ years $(37,19 \%), 3-5$ years $(38,7.4 \%)$, and over 5 years $(13,6.7 \%)$. The number of those who tried to become pregnant for less than one year was the highest (74, 40\%), followed by $1-2$ years $(49,26.5 \%), 2-3$ years $(37,20 \%), 3-5$ years $(19,10.3 \%), 5-10$ years $(4,2.2 \%)$, and over 10 years $(2,1.1 \%)$. The number of those who were treated for subfertility for less than one year was the highest $(95,47.5 \%)$, followed by $1-2$ years $(49,24.5 \%), 2-3$ years $(37,19 \%)$, $3-4$ years $(14,7 \%), 4-5$ years $(9,4.5 \%)$, and over 5 years $(6,3 \%)$. The number of those who did not have any experience of pregnancy was 111 (55.5\%), and 87 women (43.5\%) answered that they had the experience. In terms of subfertility treatments that they tried before, artificial insemination accounted for the largest $(85,47.2 \%)$, followed by test tube $(51,28.3 \%)$, and others $(44,24.4 \%)$. In terms of the cause of subfertility, male chromosome abnormality accounted for the largest $(74,37.8 \%)$, followed by ovulation disorder $(29,14.8 \%)$, and unknown $(25,12.8 \%)$.

\section{Questionnaire composition}

In terms of the emotional characteristics of subfertile women, six questions (pressure to become pregnant; anxiety and fear; depression, hopelessness, helplessness, loneliness and sadness; shame and guilt; impatience and frustration; and anger and sensitivity) were developed based on Kim et al. (2011) and Kang (2015) as they researched the overall emotions of subfertile women. The reliability coefficient (Cronbach's $\alpha$ ) of the emotional characteristics of subfertile women was .88. About the preference of participants for forest therapy programs, 33 questions were developed based on the questionnaires developed by Kim (2015) and Park (2018) for analyzing needs as follows: seven questions about exercise-focused programs; two questions about water-focused programs; three questions about diet-focused programs; four questions about plant-focused programs; four questions about climate-focused programs; and 13 questions about mental health-focused programs. A total of 39 questions were developed to survey the emotional characteristics of subfertile women and their preference for forest therapy programs, and were reviewed by experts of forest therapy and subfertility. In this process, some programs mentioned in questions in the earlier studies were replaced with programs that were more effective and suitable for subfertile women. For instance, forest field day was replaced with pelvic exercise walking; drinking herbal teas with drinking herbal teas good for pregnancy; and personal relations with Domar relaxation therapy. The content of the questionnaire was listed in detail in Table 1.

\section{Data analysis}

The data collected in this study were analyzed using SPSS 21.0, and frequency analysis and cross tabulation analysis were conducted to analyze subfertile women's preference for forest therapy programs depending on their emotional characteristics. 
Table 1. Survey contents for subfertile women

\begin{tabular}{|c|c|c|c|}
\hline Contents & & Category & Number of questions \\
\hline $\begin{array}{c}\text { Emotional } \\
\text { characteristics }\end{array}$ & \multicolumn{2}{|c|}{$\begin{array}{l}\text { Pressured to become pregnant / anxiety, fear / depression, hopelessness, helplessness, loneliness, } \\
\text { sadness / impatience, frustration / shame, guilt / anger, sensitivity }\end{array}$} & 6 \\
\hline \multirow{6}{*}{$\begin{array}{l}\text { Preferred } \\
\text { forest } \\
\text { therapy } \\
\text { program }\end{array}$} & Excercise-focused & $\begin{array}{l}\text { Breathing / breathing exercises, yoga, barefoot walking in the woods, } \\
\text { walk freely in the forest (wearing shoes), mountain climbing, mountain } \\
\text { walking in silence, pelvic exercise walking }\end{array}$ & 7 \\
\hline & Water-focused & $\begin{array}{l}\text { Lower body bathing / foot bath / hot spring bath, listening to water } \\
\text { sounds/ hand and foot soak }\end{array}$ & 2 \\
\hline & Diet-focused & Drinking good herbal tea for pregnancy, eating organic foods, making food & 3 \\
\hline & Mental, health-focused & $\begin{array}{l}\text { Self-esteem recovery program, counseling/coaching, stress lecture } \\
\text { (coping skills), Domar relaxation therapy, meditation(mindfulness, } \\
\text { MBSR), NLP therapy, cognitive behavior therapy, couple therapy/ } \\
\text { family therapy, aroma therapy, sleeping in the woods, reading in forest } \\
\text { / writing therapy, integrated art therapy in the forest (art, music, } \\
\text { movement, laughter, theater), horticulture in the forest }\end{array}$ & 13 \\
\hline & Plant-focused & $\begin{array}{l}\text { Viewing landscape, listening to the forest commentary, healing plant } \\
\text { observation/storytelling, making natural products }\end{array}$ & 4 \\
\hline & Climate-focused & $\begin{array}{l}\text { Forest bathing / wind bathing / sunbathing, a deep breath of air } \\
\text { /phytoncide, camping, observing stars }\end{array}$ & 4 \\
\hline & & Total & 39 \\
\hline
\end{tabular}

\section{Results and Discussion}

\section{Emotional characteristics of subfertile women}

The level of pressure that subfertile women felt to become pregnant tended to be high as follows: medium, $47.5 \%$; high, 35.5\%; and very high, $10 \%$ (Table 2). The level of anxiety and fear was medium in general as follows: medium, 56.5\%; high, $25.5 \%$; and low $18 \%$, and that of depression, hopelessness, helplessness, loneliness and sadness also tended to be medium as follows: medium, $48 \%$; low, 32.5\%; and high, 19.5\%. The level of shame and guilt was low in general as follows: low, 32.5\%; medium, 37.7\%; and high, $12.1 \%$. The level of impatience and frustration tended to be low as follows: medium, 46.5\%; high, 33\%; and low, $20.5 \%$. When the level of emotional difficulties that subfertile women felt was divided into high, medium and low, the item of which "high" share was the highest was anger and sensitivity (33\%), followed by depression, hopelessness, helplessness, loneliness and sadness (22.5\%). and that of which "medium" share was the highest was depression, hopelessness, helplessness, loneliness and sadness
Table 2. Emotional characteristics of subfertile women related to subfertility $(\mathrm{N}=200)$

\begin{tabular}{|c|c|c|c|}
\hline Category & Degree & Frequency & Percent (\%) \\
\hline \multirow{5}{*}{$\begin{array}{l}\text { Pressured to become } \\
\text { pregnant }\end{array}$} & Very high & 20 & 10.0 \\
\hline & High & 71 & 35.5 \\
\hline & Medium & 95 & 47.5 \\
\hline & Low & 14 & 7.0 \\
\hline & very low & 0 & 0.0 \\
\hline \multirow{3}{*}{ Anxiety and fear } & High & 51 & 25.5 \\
\hline & Medium & 113 & 56.5 \\
\hline & Low & 36 & 18.0 \\
\hline \multirow{3}{*}{$\begin{array}{l}\text { Depression, hopelessness, } \\
\text { helplessness, loneliness } \\
\text { and sadness }\end{array}$} & High & 39 & 19.5 \\
\hline & Medium & 96 & 48.0 \\
\hline & Low & 65 & 32.5 \\
\hline \multirow{3}{*}{ Shame and guilt } & High & 24 & 12.1 \\
\hline & Medium & 75 & 37.7 \\
\hline & Low & 100 & 50.3 \\
\hline \multirow{3}{*}{ Impatience and frustration } & High & 66 & 33.0 \\
\hline & Medium & 93 & 46.5 \\
\hline & Low & 41 & 20.5 \\
\hline \multirow{3}{*}{ Anger and sensitivity } & High & 39 & 19.5 \\
\hline & Medium & 101 & 50.5 \\
\hline & Low & 60 & 30.0 \\
\hline
\end{tabular}


(56.5\%), followed by shame and guilt (48\%). The item of which "low" share was the highest was impatience and frustration $(50.3 \%)$, followed by anxiety and fear (47.5\%). These results were similar with the result of Kang (2015) on the emotional characteristics of subfertile women that the level of pressure that they felt to become pregnant tended to be high.

\section{Preference of subfertile women for forest therapy programs}

\section{Preference of subfertile women for forest therapy programs}

The preference of subfertile women for forest therapy programs surveyed in this study was as shown in Table 3. The program that showed the highest mean value was

Table 3. Forest therapy program process requirements for subfertile women

\begin{tabular}{|c|c|c|c|}
\hline Variable & Category & M & SD \\
\hline \multirow{7}{*}{$\begin{array}{c}\text { Exercise-focused } \\
\text { program }\end{array}$} & Breathing / breathing exercises & 4.06 & 0.73 \\
\hline & Yoga & 3.73 & 0.83 \\
\hline & Walking barefoot in the woods & 3.52 & 0.89 \\
\hline & Walking freely in the forest (wearing shoes) & 3.96 & 0.75 \\
\hline & Mountain climbing & 3.07 & 0.89 \\
\hline & Mountain walking in silence & 2.81 & 1.04 \\
\hline & Pelvic exercise walking & 3.62 & 0.82 \\
\hline \multirow{2}{*}{$\begin{array}{l}\text { Water-focused } \\
\text { program }\end{array}$} & Lower body bathing / foot bath / hot spring bath & 4.16 & 0.78 \\
\hline & Listening to water sounds / hand and foot soak & 3.80 & 0.92 \\
\hline \multirow{3}{*}{$\begin{array}{l}\text { Diet-focused } \\
\text { program }\end{array}$} & Drinking good herbal tea for pregnancy & 4.05 & 0.83 \\
\hline & Eating organic foods & 4.17 & 0.86 \\
\hline & Making food & 3.53 & 1.02 \\
\hline \multirow{13}{*}{$\begin{array}{l}\text { Mental-focused } \\
\text { program }\end{array}$} & Self-esteem recovery program & 4.20 & 0.79 \\
\hline & Counseling / coaching & 4.00 & 0.84 \\
\hline & Stress lecture (coping skills) & 4.04 & 0.83 \\
\hline & Domar relaxation therapy & 3.96 & 0.80 \\
\hline & Meditation (mindfulness, MBSR) & 3.98 & 0.82 \\
\hline & NLP therapy & 3.46 & 0.81 \\
\hline & Cognitive behavior therapy & 3.49 & 0.90 \\
\hline & Couple therapy / family therapy & 3.99 & 0.89 \\
\hline & Aroma therapy & 3.80 & 0.94 \\
\hline & Sleeping in the woods & 3.43 & 1.07 \\
\hline & Reading in forest / writing therapy & 3.24 & 1.01 \\
\hline & Integrated art therapy in the forest (art, music, movement, laughter, theater) & 3.41 & 1.00 \\
\hline & Horticulture in the forest & 3.37 & 0.95 \\
\hline \multirow{4}{*}{$\begin{array}{c}\text { Plant-focused } \\
\text { program }\end{array}$} & Viewing landscape & 3.91 & 0.89 \\
\hline & Listening to the forest commentary & 3.24 & 0.97 \\
\hline & Healing plant observation / storytelling & 3.41 & 1.02 \\
\hline & Making natural products & 3.23 & 0.98 \\
\hline \multirow{4}{*}{$\begin{array}{l}\text { Climate-focused } \\
\text { program }\end{array}$} & Forest bathing / wind bathing / sunbathing & 4.30 & 0.71 \\
\hline & A deep breath of air / phytoncide & 4.41 & 0.68 \\
\hline & Camping & 3.12 & 1.14 \\
\hline & Observing stars & 3.46 & 1.05 \\
\hline
\end{tabular}


a deep breath of air /phytoncide (4.41), followed by forest bathing/wind bathing/sunbathing (4.30), self-esteem recovery program (4.20), eating organic foods (4.17), lower body bathing/foot bathing/hot spring bath (4.16), breathing/breathing exercises (4.06), drinking good herbal teas for pregnancy (4.05), stress lecture(coping skills; 4.04), counseling/coaching (4), couple therapy/family therapy (3.99), meditation (mindfulness, MBSR) (3.98), walking freely in forests (wearing shoes; 3.96), Domar relaxation therapy (3.96), viewing landscape (3.91), listening to water sounds/hand and foot soak(3.80), aroma therapy (3.80), yoga (3.73), pelvic exercise walking (3.62), making food (3.53), walking barefoot in woods (3.52), cognitive behavior therapy (3.49), NLP(Neuro-linguistic programming) therapy (3.46), observing stars (3.46), sleeping in the woods (3.43), integrated art therapy in forests (3.41), healing plants observing /storytelling (3.41), horticultural therapy in forest (3.37), listening to forest commentary (3.24), writing therapy in forests (3.24), making natural products (3.23), camping (3.12), mountain climbing (3.07), and mountain walking in silence (2.81). The top six programs that were the most preferred included a deep breath of air /phytoncide, forest bathing/wind bathing/sun bathing, self-esteem recovery program, eating organic foods, lower body bathing/foot bathing/hot spring bathing, and breathing/breathing exercises, which coincided with the results of Kim (2015) and Park (2018) on preferred forest therapy programs that forest bathing, wind bathing and sunbathing were preferred.

\section{Differences in preference for forest therapy programs depending on the emotional characteristics of subfertile women}

Differences in the preference of subfertile women for forest therapy programs depending on their emotional characteristics were identified, and emotions and preferred programs that showed significant differences were found to be as follows:

\section{(1) Pressured to become pregnant}

The subfertile women who felt pressure to become pregnant showed significant differences in their preference for the following programs (Table 4): mountain climbing $\left(\chi^{2}=27.702\right.$, $p<.01)$, self-esteem recovery program $\left(\chi^{2}=16.773, p<.05\right)$,
Domar relaxation therapy $\left(\chi^{2}=21.428, p<.05\right)$, NLP therapy $\left(\chi^{2}=14.454, p<.05\right)$, and sleeping in the woods $\left(\chi^{2}=23.814\right.$, $p<.05)$. When the level of pressure to become pregnant was medium, respondents were found to prefer NLP therapy $(29.9 \%)$, mountain climbing $(25.3 \%)$ and sleeping in the woods $(22.2 \%)$ as medium, and self-esteem recovery program $(22.3 \%)$ and Domar relaxation therapy $(19.3 \%)$ as important. In terms of pressure to become pregnant, respondents were found to prefer the self-esteem recovery program the most.

\section{(2) Anxiety and fear}

The subfertile women who had anxiety and fear showed significant differences in their preference for the following programs (Table 5): walking barefoot in forests $\left(\chi^{2}=18.450\right.$, $p<.05)$, mountain walking in silence $\left(\chi^{2}=16.777, p<.05\right)$, listening to water sounds/hand and foot soak $\left(\chi^{2}=21.172\right.$, $p<.01)$, self-esteem recovery program $\left(\chi^{2}=18.446, p<.01\right)$, NLP therapy $\left(\chi^{2}=27.459, p<.01\right)$, cognitive behavior therapy $\left(\chi^{2}=21.294, p<.01\right)$, aroma therapy $\left(\chi^{2}=16.105, p<.05\right)$, integrated art therapy in forests $\left(\chi^{2}=16.385, p<.05\right)$, forest bathing/wind bathing/sunbathing ( $\left.\chi^{2}=17.063, p<.01\right)$, a deep breath of air/phytoncide $\left(\chi^{2}=14.880, p<.05\right)$, and observing stars $\left(\chi^{2}=18.971, p<.05\right)$. When the level of anxiety and fear was medium, respondents were found to prefer a deep breath of air/phytoncide (29\%) as very important, and self-esteem recovery program $(26.3 \%)$, aroma therapy $(25.9 \%)$, listening to water sounds/hand and foot soak $(25.6 \%)$, and walking barefoot in forests $(25 \%)$ as important. When the level of anxiety and fear was medium, subfertile women were found to prefer forest bathing/wind bathing/sunbathing (31.4\%), NLP therapy (31.3\%), cognitive behavior therapy $(27.8 \%)$, mountain walking in silence $(26.1 \%)$, integrated art therapy in forests $(24.6 \%)$ and observing stars $(23.5 \%)$ as medium. When the level of anxiety and fear was medium, respondents were found to prefer walking barefoot in forests (bare feet), listening to water sounds/ hand and foot soak, self-esteem recovery program, aroma therapy, and forest bathing/wind bathing/sunbathing as important, and a deep breath of air/phytoncide as very important. They preferred mountain walking in silence, NLP therapy, cognitive behavior therapy, 
Table 4. Preferences for forest therapy programs depending on the pressure to become pregnant of subfertile women

\begin{tabular}{|c|c|c|c|c|c|c|c|}
\hline & \multirow{2}{*}{ Variable } & \multicolumn{5}{|c|}{ Frequency $(\%)$} & \multirow{2}{*}{$\chi^{2}(p)$} \\
\hline & & Very high & High & Medium & Low & Total & \\
\hline \multirow{6}{*}{$\begin{array}{l}\text { Mountain } \\
\text { climbing }\end{array}$} & It does not matter at all & $1(0.6)$ & $0(0)$ & $3(1.8)$ & $2(1.2)$ & $6(3.6)$ & \multirow{6}{*}{$\begin{array}{c}27.702 \\
\left(.006^{* *}\right)\end{array}$} \\
\hline & It is not important & $5(3.0)$ & $9(5.4)$ & $17(10.2)$ & $2(1.2)$ & $33(19.9)$ & \\
\hline & It is average & $4(2.4)$ & $31(18.7)$ & $42(25.3)$ & $3(1.8)$ & $80(48.2)$ & \\
\hline & It is important & $4(2.4)$ & $17(10.2)$ & $14(8.4)$ & $3(1.8)$ & $38(22.9)$ & \\
\hline & It is very important & $2(2.4)$ & $2(1.2)$ & $3(1.8)$ & $0(0)$ & $9(5.4)$ & \\
\hline & Total & $18(10.8)$ & $59(35.5)$ & $79(47.6)$ & $10(6)$ & $166(100)$ & \\
\hline \multirow{5}{*}{$\begin{array}{c}\text { Self-esteem } \\
\text { recovery } \\
\text { program }\end{array}$} & It is not important & $0(0)$ & $1(0.6)$ & $3(1.7)$ & $0(0)$ & $4(2.2)$ & \multirow{5}{*}{$\begin{array}{l}16.773 \\
\left(.05^{*}\right)\end{array}$} \\
\hline & It is average & $5(2.8)$ & $8(4.5)$ & 16(8.9) & $1(.6)$ & $30(16.8)$ & \\
\hline & It is important & $2(1.1)$ & $23(12.8)$ & $40(22.3)$ & $7(3.9)$ & $72(40.2)$ & \\
\hline & It is very important & $12(6.7)$ & $31(17.3)$ & $28(15.6)$ & $2(1.1)$ & $73(40.8)$ & \\
\hline & Total & 19(10.6) & $63(35.2)$ & $87(48.6)$ & $10(5.6)$ & $179(100)$ & \\
\hline \multirow{6}{*}{$\begin{array}{l}\text { Domar } \\
\text { relaxation } \\
\text { therapy }\end{array}$} & It does not matter at all & $1(0.6)$ & $0(0)$ & $0(0)$ & $0(0)$ & $1(0.6)$ & \multirow{6}{*}{$\begin{array}{l}21.428 \\
\left(.044^{*}\right)\end{array}$} \\
\hline & It is not important & $0(0)$ & $0(0)$ & $3(1.8)$ & $0(0)$ & $3(1.8)$ & \\
\hline & It is average & $4(2.4)$ & $11(6.6)$ & $24(14.5)$ & $2(1.2)$ & $41(24.7)$ & \\
\hline & It is important & $5(3.0)$ & $35(21.1)$ & $32(19.3)$ & $6(3.6)$ & $78(47.0)$ & \\
\hline & It is very important & $8(4.8)$ & $14(8.4)$ & $20(12.0)$ & $1(0.6)$ & $43(25.9)$ & \\
\hline & Total & $18(10.8)$ & $60(36.1)$ & $79(47.6)$ & $9(5.4)$ & $166(100)$ & \\
\hline \multirow{6}{*}{$\begin{array}{l}\text { NLP } \\
\text { therapy }\end{array}$} & It does not matter at all & $0(0)$ & $2(1.4)$ & $0(0)$ & $0(0)$ & $2(1.4)$ & \multirow{6}{*}{$\begin{array}{l}14.454 \\
\left(.018^{*}\right)\end{array}$} \\
\hline & It is not important & $0(0)$ & $1(0.7)$ & $2(1.4)$ & $2(1.4)$ & $5(3.5)$ & \\
\hline & It is average & $10(6.9)$ & $25(17.4)$ & $43(29.9)$ & $2(1.4)$ & $80(55.6)$ & \\
\hline & It is important & $3(2.1)$ & $12(8.3)$ & $22(15.3)$ & $2(1.4)$ & $39(27.1)$ & \\
\hline & It is very important & $5(3.5)$ & $6(4.2)$ & $6(4.2)$ & $1(.7)$ & $18(12.5)$ & \\
\hline & Total & $18(12.5)$ & 49(31.9) & $73(50.7)$ & $7(4.9)$ & $144(100)$ & \\
\hline \multirow{6}{*}{$\begin{array}{l}\text { Sleeping in the } \\
\text { woods }\end{array}$} & It does not matter at all & $0(0)$ & $3(1.8)$ & $1(0.6)$ & $2(1.2)$ & $6(3.6)$ & \multirow{6}{*}{$\begin{array}{l}23.814 \\
(.022 *)\end{array}$} \\
\hline & It is not important & $2(1.2)$ & $4(2.4)$ & $13(7.8)$ & $2(1.2)$ & $21(12.6)$ & \\
\hline & It is average & $4(2.4)$ & $26(15.6)$ & $37(22.2)$ & $4(2.4)$ & $71(42.5)$ & \\
\hline & It is important & $4(2.4)$ & $14(8.4)$ & $15(9)$ & $1(0.6)$ & $34(20.4)$ & \\
\hline & It is very important & $9(5.4)$ & $12(7.2)$ & $13(7.8)$ & $1(0.6)$ & $35(21)$ & \\
\hline & Total & 19(11.4) & $59(35.3)$ & $79(47.3)$ & $10(6)$ & $167(100)$ & \\
\hline
\end{tabular}

$* p<.05, * * p<.01$ by ${ }^{2}$ test.

integrated art therapy in forests, and observing stars as medium, when the level of anxiety and fear was medium. In terms of anxiety and fear, respondents were found to prefer self-esteem recovery program, a deep breath of air/phytoncide and forest bathing/wind bathing/sunbathing the most.

(3) Depression, hopelessness, helplessness, loneliness and sadness

The subfertile women who had emotions including depression, hopelessness, helplessness, loneliness and sadness showed significant differences in their preference for the following programs (Table 6): eating organic foods $\left(\chi^{2}=15.916\right.$, $p<.05)$, self-esteem recovery program $\left(\chi^{2}=13.246, p<.05\right)$, counseling/coaching ( $\left.\chi^{2}=16.197, p<.05\right)$, and cognitive behavior therapy $\left(\chi^{2}=24.044, p<.01\right)$. When the level of depression, hopelessness, helplessness, loneliness and sadness was medium, respondents were found to prefer the program of eating organic foods $(21.7 \%)$ as very important, and counseling/coaching (25.7\%), self-recovery program $(21.8 \%)$, and cognitive behavior therapy $(21.5 \%)$ as important. In terms of emotions including depression, hopelessness, 
Table 5. Preferences for forest therapy programs depending on anxiety and fear of subfertile women

\begin{tabular}{|c|c|c|c|c|c|c|}
\hline & \multirow{2}{*}{ Variable } & \multicolumn{4}{|c|}{ Frequency (\%) } & \multirow{2}{*}{$\chi^{2}(p)$} \\
\hline & & High & Medium & Low & Total & \\
\hline \multirow{6}{*}{$\begin{array}{l}\text { Walking } \\
\text { barefoot in the } \\
\text { forest }\end{array}$} & It does not matter at all & $1(0.6)$ & $1(0.6)$ & $0(0)$ & $2(1.2)$ & \multirow{6}{*}{$\begin{array}{l}18.450 \\
\left(.018^{*}\right)\end{array}$} \\
\hline & It is not important & $8(4.7)$ & $7(4.1)$ & $0(0)$ & $15(8.7)$ & \\
\hline & It is average & $15(8.7)$ & $38(22.1)$ & $18(10.5)$ & $71(41.3)$ & \\
\hline & It is important & $10(5.8)$ & $43(25)$ & $6(3.5)$ & $59(34.3)$ & \\
\hline & It is very important & $6(3.5)$ & $16(9.3)$ & $3(1.7)$ & $25(14.5)$ & \\
\hline & Total & $40(23.3)$ & $105(61)$ & $27(15.7)$ & $172(100)$ & \\
\hline \multirow{6}{*}{$\begin{array}{l}\text { Mountain } \\
\text { walking in } \\
\text { silence }\end{array}$} & It does not matter at all & $5(3)$ & $12(7.3)$ & $2(1.2)$ & $19(11.5)$ & \multirow{6}{*}{$\begin{array}{l}16.777 \\
\left(.033^{*}\right)\end{array}$} \\
\hline & It is not important & $11(6.7)$ & $22(13.3)$ & $9(5.5)$ & $42(25.5)$ & \\
\hline & It is average & $9(5.5)$ & $43(26.1)$ & $11(6.7)$ & $63(38.2)$ & \\
\hline & It is important & $10(6.1)$ & $18(10.9)$ & $5(3.0)$ & $33(20)$ & \\
\hline & It is very important & $6(3.6)$ & $2(1.2)$ & $0(0)$ & $8(4.8)$ & \\
\hline & Total & $41(24.8)$ & $97(58.8)$ & $27(16.4)$ & $165(100)$ & \\
\hline \multirow{6}{*}{$\begin{array}{c}\text { Listening to } \\
\text { water sounds/ } \\
\text { hand and foot soak }\end{array}$} & It does not matter at all & $1(0.6)$ & $0(0)$ & $0(0)$ & $1(0.6)$ & \multirow{6}{*}{$\begin{array}{c}21.172 \\
(.007 * *)\end{array}$} \\
\hline & It is not important & $5(2.9)$ & $4(2.3)$ & $2(1.2)$ & $11(6.4)$ & \\
\hline & It is average & $7(4.1)$ & $33(19.2)$ & $13(7.6)$ & $53(30.8)$ & \\
\hline & It is important & 13(7.6) & $44(25.6)$ & $6(3.5)$ & $63(36.6)$ & \\
\hline & It is very important & $18(10.5)$ & $18(10.5)$ & $8(4.7)$ & $44(25.6)$ & \\
\hline & Total & $44(25.6)$ & $99(57.6)$ & $29(16.9)$ & $172(100)$ & \\
\hline \multirow{5}{*}{$\begin{array}{c}\text { Self-esteem recovery } \\
\text { program }\end{array}$} & It is not important & $0(0)$ & $2(1.1)$ & $2(1.1)$ & $4(2.2)$ & \multirow{5}{*}{$\begin{array}{c}18.446 \\
\left(.005^{* *}\right)\end{array}$} \\
\hline & It is average & $5(2.8)$ & $20(11.2)$ & $5(2.8)$ & $30(16.8)$ & \\
\hline & It is important & $11(6.1)$ & $47(26.3)$ & $14(7.8)$ & $72(40.2)$ & \\
\hline & It is very important & $30(16.8)$ & $35(19.6)$ & $8(4.5)$ & $73(40.8)$ & \\
\hline & Total & $46(25.7)$ & $104(58.1)$ & $29(16.2)$ & $179(100)$ & \\
\hline \multirow{6}{*}{ NLP therapy } & It does not matter at all & $2(1.4)$ & $0(0)$ & $0(0)$ & $2(1.4)$ & \multirow{6}{*}{$\begin{array}{c}27.459 \\
(.001 * * *)\end{array}$} \\
\hline & It is not important & $0(0)$ & $2(1.4)$ & $3(2.1)$ & $5(3.5)$ & \\
\hline & It is average & $18(12.5)$ & $45(31.3)$ & 17(11.8) & $80(55.6)$ & \\
\hline & It is important & $7(4.9)$ & $30(20.8)$ & $2(1.4)$ & $39(27.1)$ & \\
\hline & It is very important & $9(6.3)$ & $8(5.6)$ & $1(.7)$ & $18(12.5)$ & \\
\hline & Total & $36(25)$ & $85(59)$ & $23(16)$ & $144(100)$ & \\
\hline \multirow{6}{*}{$\begin{array}{l}\text { Cognitive behavior } \\
\text { therapy }\end{array}$} & It does not matter at all & $2(1.3)$ & $1(0.6)$ & $1(0.6)$ & $4(2.5)$ & \multirow{6}{*}{$\begin{array}{c}21.294 \\
\left(.006^{* *}\right)\end{array}$} \\
\hline & It is not important & $1(0.6)$ & $3(1.9)$ & $6(3.8)$ & $10(6.3)$ & \\
\hline & It is average & $14(8.9)$ & $44(27.8)$ & $13(8.2)$ & $71(44.9)$ & \\
\hline & It is important & $13(8.2)$ & $33(20.9)$ & $5(3.2)$ & $51(32.3)$ & \\
\hline & It is very important & $9(5.7)$ & $11(7)$ & $2(1.3)$ & $22(13.9)$ & \\
\hline & Total & $39(24.7)$ & $92(58.2)$ & $27(17.1)$ & $158(100)$ & \\
\hline \multirow{6}{*}{ Aroma therapy } & It does not matter at all & $2(1.2)$ & $3(1.8)$ & $0(0)$ & $5(2.9)$ & \multirow{6}{*}{$\begin{array}{l}16.105 \\
\left(.041^{*}\right)\end{array}$} \\
\hline & It is not important & $0(0)$ & $3(1.8)$ & $1(0.6)$ & $4(2.4)$ & \\
\hline & It is average & $15(8.8)$ & $26(15.3)$ & $12(7.1)$ & $53(31.2)$ & \\
\hline & It is important & $8(4.7)$ & $44(25.9)$ & $14(8.2)$ & $66(38.8)$ & \\
\hline & It is very important & $17(10)$ & $21(12.4)$ & $4(2.4)$ & $42(24.7)$ & \\
\hline & Total & $42(24.7)$ & $97(57.1)$ & $31(18.2)$ & $170(100)$ & \\
\hline
\end{tabular}


Table 5. (continued)

\begin{tabular}{|c|c|c|c|c|c|c|}
\hline & \multirow{2}{*}{ Variable } & \multicolumn{4}{|c|}{ Frequency $(\%)$} & \multirow{2}{*}{$\chi^{2}(p)$} \\
\hline & & High & Medium & Low & Total & \\
\hline \multirow{6}{*}{$\begin{array}{l}\text { Integrated art } \\
\text { therapy in the forest } \\
\text { laughter, theater) } \\
\text { (art, music, movement, }\end{array}$} & It does not matter at all & $0(0)$ & $2(1.2)$ & $2(1.2)$ & $4(2.4)$ & \multirow{6}{*}{$\begin{array}{l}16.385 \\
\left(.037^{*}\right)\end{array}$} \\
\hline & It is not important & $6(3.6)$ & $11(6.6)$ & $5(3)$ & $22(13.2)$ & \\
\hline & It is average & $16(9.6)$ & $41(24.6)$ & $13(7.8)$ & $70(41.9)$ & \\
\hline & It is important & $7(4.2)$ & $33(19.8)$ & $3(1.8)$ & $43(25.7)$ & \\
\hline & It is very important & $12(7.2)$ & $11(6.6)$ & $5(3)$ & $28(16.8)$ & \\
\hline & Total & $41(24.6)$ & $98(58.7)$ & $28(16.8)$ & $167(100)$ & \\
\hline \multirow{5}{*}{$\begin{array}{l}\text { Forest bathing / } \\
\text { wind bathing / } \\
\text { sunbathing }\end{array}$} & It does not matter at all & $0(0)$ & $1(0.6)$ & $0(0)$ & $1(0.6)$ & \multirow{5}{*}{$\begin{array}{c}17.063 \\
(.009 * *)\end{array}$} \\
\hline & It is not important & $6(3.4)$ & $8(4.6)$ & $8(4.6)$ & $22(12.6)$ & \\
\hline & It is average & $11(6.3)$ & $55(31.4)$ & $10(5.7)$ & $76(43.4)$ & \\
\hline & It is important & $25(14.3)$ & $41(23.4)$ & $10(5.7)$ & $76(43.4)$ & \\
\hline & Total & $42(24)$ & $105(60)$ & $28(16)$ & $175(100)$ & \\
\hline \multirow{5}{*}{$\begin{array}{l}\text { A deep breath of air / } \\
\text { phytoncide }\end{array}$} & It is not important & $0(0)$ & $1(0.6)$ & $0(0)$ & $1(0.6)$ & \multirow{5}{*}{$\begin{array}{l}14.880 \\
\left(.021^{*}\right)\end{array}$} \\
\hline & It is average & $5(2.8)$ & $4(2.3)$ & $7(4.0)$ & $16(9.1)$ & \\
\hline & It is important & $11(6.3)$ & $47(26.7)$ & $11(6.3)$ & $69(39.2)$ & \\
\hline & It is very important & $26(14.8)$ & $51(29.0)$ & $13(7.4)$ & $90(51.1)$ & \\
\hline & Total & $42(23.9)$ & $103(58.5)$ & $31(17.6)$ & $176(100)$ & \\
\hline \multirow{6}{*}{$\begin{array}{l}\text { Observing } \\
\text { stars }\end{array}$} & It does not matter at all & $6(3.6)$ & $1(0.6)$ & $0(0)$ & $7(4.2)$ & \multirow{6}{*}{$\begin{array}{l}18.971 \\
\left(.015^{*}\right)\end{array}$} \\
\hline & It is not important & $2(1.2)$ & $13(7.8)$ & $3(1.8)$ & $18(10.8)$ & \\
\hline & It is average & $13(7.8)$ & $39(23.5)$ & $12(7.2)$ & $64(38.6)$ & \\
\hline & It is important & $10(6)$ & $30(18.1)$ & $6(3.6)$ & $46(27.7)$ & \\
\hline & It is very important & $10(6)$ & $15(9)$ & $6(3.6)$ & $31(18.7)$ & \\
\hline & Total & $41(24.7)$ & $98(59)$ & $27(16.3)$ & $166(100)$ & \\
\hline
\end{tabular}

${ }^{*} p<.05,{ }^{* *} p<.01,{ }^{* * *} p<.001$ by $\mathrm{x}^{2}$ test.

helplessness, loneliness and sadness, respondents tended to prefer the programs of self-esteem recovery and eating organic foods.

\section{(4) Shame and guilt}

The subfertile women who felt shame and guilt showed significant differences in their preference for the following programs (Table 7): half bathing/foot bathing/hot spring bathing ( $\left.\chi^{2}=15.806, p<.05\right)$, stress-control skills (lecture) $\left(\chi^{2}=19.752, p<.01\right)$, and observing stars $\left(\chi^{2}=29.724\right.$, $p<.001)$. When the level of shame and guilt was medium, respondents were found to prefer half bathing/foot bathing/hot spring bathing (23.2\%) and stress-control skills lecture $(21.1 \%)$ as important, and observing stars $(22.4 \%)$ as medium. In terms of emotions including shame and guilt, respondents tended to prefer the programs of half bath- ing/foot bathing/hot spring bathing and stress-control skills.

(5) Impatience and frustration

The subfertile women who had impatience and frustration showed significant differences in their preference for the following programs (Table 8): pelvic exercise walking $\left(\chi^{2}=15.346, p<.05\right)$, lower body bathing/foot bathing/hot spring bathing $\left(\chi^{2}=17.490, p<.05\right)$, listening to water sounds/hand and foot soak $\left(\chi^{2}=22.493, p<.01\right)$, eating organic foods $\left(\chi^{2}=16.137, p<.05\right)$, cognitive behavior therapy $\left(\chi^{2}=17.893, p<.05\right)$, aroma therapy $\left(\chi^{2}=25.017\right.$, $p<.01)$, camping $\left(\chi^{2}=16.656, p<.05\right)$, and observing stars $\left(\chi^{2}=16.950, p<.05\right)$. When the level of impatience and frustration was medium, respondents were found to prefer lower body bathing/foot bathing/hot spring bathing (25.3\%), aroma therapy (24.7\%), listening to water sounds/hand and 
Table 6. Preferences for forest therapy programs depending on depression, hopelessness, helplessness, loneliness and sadness of subfertile women

\begin{tabular}{|c|c|c|c|c|c|c|}
\hline & \multirow{2}{*}{ Variable } & \multicolumn{4}{|c|}{ Frequency (\%) } & \multirow{2}{*}{$\chi^{2}(p)$} \\
\hline & & High & Medium & Low & Total & \\
\hline \multirow{6}{*}{$\begin{array}{c}\text { Eating } \\
\text { organic } \\
\text { foods }\end{array}$} & It does not matter at all & $0(0)$ & $0(0)$ & $1(0.6)$ & $1(0.6)$ & \multirow{6}{*}{$\begin{array}{l}15.916 \\
\left(.044^{*}\right)\end{array}$} \\
\hline & It is not important & $0(0)$ & $3(1.7)$ & $1(0.6)$ & $4(2.3)$ & \\
\hline & It is average & $5(2.9)$ & $11(6.3)$ & $18(10.3)$ & $34(19.4)$ & \\
\hline & It is important & $12(6.9)$ & $37(21.1)$ & $13(7.4)$ & $62(35.4)$ & \\
\hline & It is very important & $17(9.7)$ & $38(21.7)$ & $19(10.9)$ & $74(42.3)$ & \\
\hline & Total & $34(19.4)$ & $89(50.9)$ & $52(29.7)$ & $174(100)$ & \\
\hline \multirow{5}{*}{$\begin{array}{c}\text { Self-esteem } \\
\text { recovery } \\
\text { program }\end{array}$} & It is not important & $0(0)$ & $1(0.6)$ & $3(1.7)$ & $4(2.2)$ & \multirow{5}{*}{$\begin{array}{l}13.246 \\
(.039 *)\end{array}$} \\
\hline & It is average & $5(2.8)$ & $11(6.1)$ & $14(7.8)$ & $30(16.8)$ & \\
\hline & It is important & $11(6.1)$ & $39(21.8)$ & $22(12.3)$ & $72(40.2)$ & \\
\hline & It is very important & $20(11.2)$ & $38(21.2)$ & $15(8.4)$ & $73(40.8)$ & \\
\hline & Total & $36(20.1)$ & $89(49.7)$ & $54(30.2)$ & $179(100)$ & \\
\hline \multirow{6}{*}{$\begin{array}{c}\text { Counseling / } \\
\text { coaching }\end{array}$} & It does not matter at all & $0(0)$ & $1(0.6)$ & $0(0)$ & $1(0.6)$ & \multirow{6}{*}{$\begin{array}{l}16.197 \\
\left(.040^{*}\right)\end{array}$} \\
\hline & It is not important & $0(0)$ & $3(1.8)$ & $2(1.2)$ & $5(2.9)$ & \\
\hline & It is average & $10(5.8)$ & $10(5.8)$ & $19(11.1)$ & $39(22.8)$ & \\
\hline & It is important & $12(7)$ & $44(25.7)$ & $18(10.5)$ & $74(43.3)$ & \\
\hline & It is very important & $14(8.2)$ & $25(14.6)$ & $13(7.6)$ & $52(30.4)$ & \\
\hline & Total & $36(21.1)$ & $83(48.5)$ & $52(30.4)$ & $171(100)$ & \\
\hline \multirow{6}{*}{$\begin{array}{c}\text { Cognitive } \\
\text { behavior } \\
\text { therapy }\end{array}$} & It does not matter at all & $2(1.3)$ & $1(0.6)$ & $1(0.6)$ & $4(2.5)$ & \multirow{6}{*}{$\begin{array}{c}24.044 \\
(.002 * *)\end{array}$} \\
\hline & It is not important & $0(0)$ & $2(1.3)$ & $8(5.1)$ & $10(6.3)$ & \\
\hline & It is average & $14(8.9)$ & $32(20.3)$ & $25(15.8)$ & $71(44.9)$ & \\
\hline & It is important & $8(5.1)$ & $34(21.5)$ & $9(5.7)$ & $51(32.3)$ & \\
\hline & It is very important & $7(4.4)$ & $11(7)$ & $4(2.5)$ & $22(13.9)$ & \\
\hline & Total & $31(19.6)$ & $80(50.6)$ & $47(29.7)$ & $158(100)$ & \\
\hline
\end{tabular}

${ }^{*} p<.05, * * p<.01$ by $\mathrm{x}^{2}$ test.

Table 7. Preferences for forest therapy programs depending on shame and guilt of subfertile women

\begin{tabular}{|c|c|c|c|c|c|c|}
\hline & \multirow{2}{*}{ Variable } & \multicolumn{4}{|c|}{ Frequency $(\%)$} & \multirow{2}{*}{$\chi^{2}(p)$} \\
\hline & & High & Medium & Low & Total & \\
\hline \multirow{6}{*}{$\begin{array}{c}\text { Lower body bathing / } \\
\text { foot bathing / } \\
\text { hot spring bath }\end{array}$} & It does not matter at all & $1(0.6)$ & $0(0)$ & $0(0)$ & $1(0.6)$ & \multirow{6}{*}{$\begin{array}{l}15.806 \\
\left(.045^{*}\right)\end{array}$} \\
\hline & It is not important & $1(0.6)$ & $0(.0)$ & $2(1.1)$ & $3(1.7)$ & \\
\hline & It is average & $0(0)$ & $9(5.1)$ & $15(8.5)$ & $24(13.6)$ & \\
\hline & It is important & $9(5.1)$ & $35(19.8)$ & $41(23.2)$ & $85(48.0)$ & \\
\hline & It is very important & $12(6.8)$ & $20(11.3)$ & $32(18.1)$ & $64(36.2)$ & \\
\hline & Total & $23(13.0)$ & $64(36.2)$ & $90(50.8)$ & $177(100)$ & \\
\hline \multirow{6}{*}{$\begin{array}{l}\text { Stress-control } \\
\text { skills lecture }\end{array}$} & It does not matter at all & $0(0.6)$ & $0(0)$ & $0(0)$ & $1(0.6)$ & \multirow{6}{*}{$\begin{array}{c}19.752 \\
\left(.011^{* *}\right)\end{array}$} \\
\hline & It is not important & $1(0.6)$ & $2(1.2)$ & $2(1.2)$ & $5(2.9)$ & \\
\hline & It is average & $3(1.8)$ & $7(4.1)$ & $24(14.0)$ & $34(19.9)$ & \\
\hline & It is important & $6(3.5)$ & $35(20.5)$ & $36(21.1)$ & $77(45)$ & \\
\hline & It is very important & $12(7)$ & $18(10.5)$ & $24(14)$ & $54(31.6)$ & \\
\hline & Total & $23(13.5)$ & $62(36.3)$ & $86(50.3)$ & $171(100)$ & \\
\hline \multirow{6}{*}{$\begin{array}{l}\text { Observing } \\
\text { stars }\end{array}$} & It does not matter at all & $5(3)$ & $1(0.6)$ & $1(0.6)$ & $7(4.2)$ & \multirow{6}{*}{$\begin{array}{c}29.724 \\
(.000 * * *)\end{array}$} \\
\hline & It is not important & $2(1.2)$ & $3(1.8)$ & 13(7.9) & $18(10.9)$ & \\
\hline & It is average & $5(3)$ & $21(12.7)$ & $37(22.4)$ & $63(38.2)$ & \\
\hline & It is important & $4(2.4)$ & $18(10.9)$ & $24(14.5)$ & $46(27.9)$ & \\
\hline & It is very important & $7(4.2)$ & $13(7.9)$ & $11(6.7)$ & $31(18.8)$ & \\
\hline & Total & $23(13.9)$ & $56(33.9)$ & $86(52.1)$ & $165(100)$ & \\
\hline
\end{tabular}

$* p<.05, * * p<.01, * * * p<.001$ by $\mathrm{x}^{2}$ test 
Table 8. Preferences for forest therapy programs depending on impatience and frustration of subfertile women

\begin{tabular}{|c|c|c|c|c|c|c|}
\hline & \multirow{2}{*}{ Variable } & \multicolumn{4}{|c|}{ Frequency $(\%)$} & \multirow{2}{*}{$\chi^{2}(p)$} \\
\hline & & High & Medium & Low & Total & \\
\hline \multirow{6}{*}{$\begin{array}{l}\text { Pelvic exercise } \\
\text { walking }\end{array}$} & It does not matter at all & $0(0)$ & $0(0)$ & $1(0.6)$ & $1(0.6)$ & \multirow{6}{*}{$\begin{array}{l}15.346 \\
\left(.053^{*}\right)\end{array}$} \\
\hline & It is not important & $2(1.2)$ & $5(3)$ & $3(1.8)$ & $10(6.1)$ & \\
\hline & It is average & $18(11)$ & $31(18.9)$ & $13(7.9)$ & $62(37.8)$ & \\
\hline & It is important & $21(12.8)$ & $35(21.3)$ & $13(7.9)$ & $69(42.1)$ & \\
\hline & It is very important & $13(7.9)$ & $9(5.5)$ & $0(0)$ & $22(13.4)$ & \\
\hline & Total & $54(32.9)$ & $80(48.8)$ & $30(18.3)$ & $164(100)$ & \\
\hline \multirow{6}{*}{$\begin{array}{l}\text { Lower body bathing / } \\
\text { foot bathing / } \\
\text { hot spring bath }\end{array}$} & It does not matter at all & $0(0)$ & $1(0.6)$ & $0(0)$ & $1(0.6)$ & \multirow{6}{*}{$\begin{array}{l}17.490 \\
\left(.025^{*}\right)\end{array}$} \\
\hline & It is not important & $1(0.6)$ & $1(0.6)$ & $2(1.1)$ & $4(2.2)$ & \\
\hline & It is average & $4(2.2)$ & $10(5.6)$ & $10(5.6)$ & $24(13.5)$ & \\
\hline & It is important & $27(15.2)$ & $45(25.3)$ & $13(7.3)$ & $85(47.8)$ & \\
\hline & It is very important & $29(16.3)$ & $26(14.6)$ & $9(5.1)$ & $64(36)$ & \\
\hline & Total & $61(34.3)$ & $83(46.6)$ & $34(19.1)$ & $178(100)$ & \\
\hline \multirow{6}{*}{$\begin{array}{c}\text { Listening to } \\
\text { water sounds/ } \\
\text { hand and foot soak }\end{array}$} & It does not matter at all & $1(0.6)$ & $0(0)$ & $0(0)$ & $1(0.6)$ & \multirow{6}{*}{$\begin{array}{c}22.493 \\
(.004 * *)\end{array}$} \\
\hline & It is not important & $4(2.3)$ & $4(2.3)$ & $3(1.7)$ & $11(6.4)$ & \\
\hline & It is average & $13(7.6)$ & $26(15.1)$ & $14(8.1)$ & $53(30.8)$ & \\
\hline & It is important & $16(9.3)$ & $39(22.7)$ & $8(4.7)$ & $63(36.6)$ & \\
\hline & It is very important & $25(14.5)$ & $11(6.4)$ & $8(4.7)$ & $44(25.6)$ & \\
\hline & Total & $59(34.3)$ & $80(46.5)$ & $33(19.2)$ & $172(100)$ & \\
\hline \multirow{6}{*}{$\begin{array}{c}\text { Eating } \\
\text { organic } \\
\text { foods }\end{array}$} & It does not matter at all & $0(0)$ & $0(0)$ & $1(0.6)$ & $1(0.6)$ & \multirow{6}{*}{$\begin{array}{l}16.137 \\
\left(.040^{*}\right)\end{array}$} \\
\hline & It is not important & $0(0)$ & $2(1.1)$ & $2(1.1)$ & $4(2.3)$ & \\
\hline & It is average & $6(3.4)$ & $21(12.0)$ & $7(4.0)$ & $34(19.4)$ & \\
\hline & It is important & 19(10.9) & $31(17.7)$ & $12(6.9)$ & $62(35.4)$ & \\
\hline & It is very important & $33(18.9)$ & $30(17.1)$ & $11(6.3)$ & $74(42.3)$ & \\
\hline & Total & $58(33.1)$ & $84(48)$ & $33(18.9)$ & $175(100)$ & \\
\hline \multirow{6}{*}{$\begin{array}{l}\text { Cognitive } \\
\text { behavior therapy }\end{array}$} & It does not matter at all & $3(1.9)$ & $0(0)$ & $1(0.6)$ & $4(2.5)$ & \multirow{6}{*}{$\begin{array}{l}17.893 \\
(.022 *)\end{array}$} \\
\hline & It is not important & $1(0.6)$ & $3(1.9)$ & $6(3.8)$ & $10(6.3)$ & \\
\hline & It is average & $24(15.2)$ & $37(23.4)$ & $10(6.3)$ & $71(44.9)$ & \\
\hline & It is important & $16(10.1)$ & $25(15.8)$ & $10(6.3)$ & $51(32.3)$ & \\
\hline & It is very important & $10(6.3)$ & $9(5.7)$ & $3(1.9)$ & $22(13.9)$ & \\
\hline & Total & $54(34.2)$ & $74(46.8)$ & $30(19)$ & $158(100)$ & \\
\hline \multirow{6}{*}{$\begin{array}{l}\text { Aroma } \\
\text { therapy }\end{array}$} & It does not matter at all & $4(2.4)$ & $1(0.6)$ & $0(0)$ & $5(2.9)$ & \multirow{6}{*}{$\begin{array}{r}25.017 \\
(.002 * *)\end{array}$} \\
\hline & It is not important & $0(0)$ & $3(1.8)$ & $1(0.6)$ & $4(2.4)$ & \\
\hline & It is average & $20(11.8)$ & $18(10.6)$ & $15(8.8)$ & $53(31.2)$ & \\
\hline & It is important & $12(7.1)$ & $42(24.7)$ & $12(7.1)$ & $66(38.8)$ & \\
\hline & It is very important & $21(12.4)$ & $15(8.8)$ & $6(3.5)$ & $42(24.7)$ & \\
\hline & Total & $57(33.5)$ & $79(46.5)$ & $34(20)$ & $170(100)$ & \\
\hline \multirow{6}{*}{ Camping } & It does not matter at all & $9(5.4)$ & $3(1.8)$ & $4(2.4)$ & $16(9.6)$ & \multirow{6}{*}{$\begin{array}{l}16.656 \\
\left(.034^{*}\right)\end{array}$} \\
\hline & It is not important & $4(2.4)$ & $16(9.6)$ & $7(4.2)$ & $27(16.2)$ & \\
\hline & It is average & $23(13.8)$ & $33(19.8)$ & $13(7.8)$ & $69(41.3)$ & \\
\hline & It is important & $8(4.8)$ & $18(10.8)$ & $5(3)$ & $31(18.6)$ & \\
\hline & It is very important & $13(7.8)$ & $6(3.6)$ & $5(3)$ & $24(14.4)$ & \\
\hline & Total & $57(34.1)$ & $76(45.5)$ & $34(20.4)$ & $167(100)$ & \\
\hline \multirow{6}{*}{$\begin{array}{l}\text { Observing } \\
\text { stars }\end{array}$} & It does not matter at all & $6(3.6)$ & $1(0.6)$ & $0(0)$ & $7(4.2)$ & \multirow{6}{*}{$\begin{array}{l}16.950 \\
\left(.031^{*}\right)\end{array}$} \\
\hline & It is not important & $3(1.8)$ & $12(7.2)$ & $3(1.8)$ & $18(10.8)$ & \\
\hline & It is average & $18(108)$ & $29(17.5)$ & $17(10.2)$ & $64(38.6)$ & \\
\hline & It is important & $17(10.2)$ & $23(13.9)$ & $6(3.6)$ & $46(27.7)$ & \\
\hline & It is very important & $14(8.4)$ & $11(6.6)$ & $6(3.6)$ & $31(18.7)$ & \\
\hline & Total & $58(34.9)$ & $76(45.8)$ & $32(19.3)$ & $166(100)$ & \\
\hline
\end{tabular}


Table 9. Preferences for forest therapy programs depending on anger and sensitivity of subfertile women

\begin{tabular}{|c|c|c|c|c|c|c|}
\hline & \multirow{2}{*}{ Variable } & \multicolumn{4}{|c|}{ Frequency $(\%)$} & \multirow{2}{*}{$\chi^{2}(p)$} \\
\hline & & High & Medium & Low & Total & \\
\hline \multirow{6}{*}{$\begin{array}{l}\text { Pelvic exercise } \\
\text { walking }\end{array}$} & It does not matter at all & $0(0)$ & $0(0)$ & $1(0.6)$ & $1(0.6)$ & \multirow{6}{*}{$\begin{array}{c}20.046 \\
\left(.010^{* *}\right)\end{array}$} \\
\hline & It is not important & $3(1.8)$ & $2(1.2)$ & $5(3)$ & $10(6.1)$ & \\
\hline & It is average & $8(4.9)$ & $39(23.8)$ & $15(9.1)$ & $62(37.8)$ & \\
\hline & It is important & $12(7.3)$ & $33(20.1)$ & $24(14.6)$ & $69(42.1)$ & \\
\hline & It is very important & $10(6.1)$ & $8(4.9)$ & $4(2.4)$ & $22(13.4)$ & \\
\hline & Total & $33(20.1)$ & $82(50.0)$ & $49(29.9)$ & $164(100)$ & \\
\hline \multirow{6}{*}{$\begin{array}{l}\text { Lower body bathing / } \\
\text { foot bathing / } \\
\text { hot spring bath }\end{array}$} & It does not matter at all & $1(0.6)$ & $0(0)$ & $0(0)$ & $1(0.6)$ & \multirow{6}{*}{$\begin{array}{l}18.045 \\
\left(.021^{*}\right)\end{array}$} \\
\hline & It is not important & $2(1.1)$ & $1(0.6)$ & $1(0.6)$ & $4(2.2)$ & \\
\hline & It is average & $0(0)$ & $11(6.2)$ & $13(7.3)$ & $24(13.5)$ & \\
\hline & It is important & $16(9)$ & $46(25.8)$ & $23(12.9)$ & $85(47.8)$ & \\
\hline & It is very important & $17(9.6)$ & $30(16.9)$ & $17(9.6)$ & $64(36)$ & \\
\hline & Total & $36(20.2)$ & $88(49.4)$ & $54(30.3)$ & $178(100)$ & \\
\hline \multirow{6}{*}{ Making food } & It does not matter at all & $2(1.2)$ & $0(0)$ & $2(1.2)$ & $4(2.4)$ & \multirow{6}{*}{$\begin{array}{l}16.649 \\
\left(.034^{*}\right)\end{array}$} \\
\hline & It is not important & $4(2.4)$ & $8(4.7)$ & $6(3.6)$ & $18(10.7)$ & \\
\hline & It is average & $12(7.1)$ & $29(17.2)$ & $27(16)$ & $68(40.2)$ & \\
\hline & It is important & $4(2.4)$ & $28(16.6)$ & $11(6.5)$ & $43(25.4)$ & \\
\hline & It is very important & $12(7.1)$ & $17(10.1)$ & $7(4.1)$ & $36(21.3)$ & \\
\hline & Total & $34(20.1)$ & $82(48.5)$ & $53(31.4)$ & $169(100)$ & \\
\hline \multirow{5}{*}{$\begin{array}{c}\text { Self-esteem recovery } \\
\text { program }\end{array}$} & It is not important & $0(0)$ & $2(1.1)$ & $2(1.1)$ & $4(2.2)$ & \multirow{5}{*}{$\begin{array}{c}21.028 \\
(.002 * *)\end{array}$} \\
\hline & It is average & $5(2.8)$ & $12(6.7)$ & $13(7.3)$ & $30(16.8)$ & \\
\hline & It is important & $7(3.9)$ & $37(20.7)$ & $28(15.6)$ & $72(40.2)$ & \\
\hline & It is very important & $24(13.4)$ & $38(21.2)$ & $11(6.1)$ & $73(40.8)$ & \\
\hline & Total & $36(20.1)$ & $89(49.7)$ & $54(30.2)$ & $179(100)$ & \\
\hline
\end{tabular}

${ }^{*} p<.05,{ }^{* *} p<.01, * * * p<.001$ by $\mathrm{x}^{2}$ test.

foot soak (22.7\%), pelvic exercise walking (21.3\%), and eating organic foods $(17.7 \%)$ as important, and cognitive behavior therapy (23.4\%), camping (19.8\%), and observing stars $(17.5 \%)$ as medium. In terms of emotions including impatience and frustration, respondents tended to prefer the programs of lower body bathing/foot bathing/hot spring bathing and eating organic foods.

\section{(6) Anger and sensitivity}

The subfertile women who had anger and sensitivity showed significant differences in their preference for the following programs (Table 9): pelvic exercise walking $\left(\chi^{2}=20.046, p<.01\right)$, lower body bathing/foot bathing/hot spring bathing $\left(\chi^{2}=18.045, p<.05\right)$, making foods $\left(\chi^{2}=16.649, p<.05\right)$, and self-esteem recovery program $\left(\chi^{2}=21.028, p<.01\right)$. When the level of anger and sensitivity was medium, respondents were found to prefer self-esteem recovery program $(21.2 \%)$ as very important; lower body bathing/foot bathing/hot spring bathing (25.8\%) as important; and pelvic exercise walking $(23.8 \%)$ and making foods (17.2\%) as medium. In terms of emotions including anger and sensitivity, respondents tended to prefer the programs of self-esteem recovery and lower body bathing/foot bathing/hot spring bathing.

\section{Conclusion}

This study was conducted to identify the preference of subfertile women for forest therapy programs depending 
on their emotional characteristics, and to provide basic data for the development of forest therapy programs in order to promote the mental and physical health of subfertile women. Among the surveyed emotional difficulties that subfertile women experienced, pressure they felt to become pregnant was found to be very high. The emotional difficulties were divided based on their level. When their emotional difficulties were high, they tended to have impatience and frustration the most, followed by anxiety and fear; depression, hopelessness, helplessness, loneliness and sadness; and anger and sensitivity. The top six programs were the most preferred by subfertile women were found to be a deep breath of air/phytoncide, forest bathing/wind bathing/sunbathing, self-esteem recovery program, eating organic foods, lower body bathing/foot bathing/hot spring bathing, and breathing/breathing exercises. Differences in the preference of subfertile women for forest therapy programs depending on their emotional characteristics were identified, and pressure to become pregnant showed significant differences between self-esteem recovery program, Domar relaxation therapy, NLP therapy and sleeping in the woods. Emotions including anxiety and fear showed significant differences between walking barefoot in forests, mountain walking in silence, listening to water sounds/hand and foot soak, self-esteem recovery program, NLP therapy, cognitive behavior therapy, aroma therapy, integrated art therapy in forests, forest bathing/wind bathing/sunbathing, a deep breath of air/phytoncide, and observing stars. Emotions including depression, hopelessness, helplessness, loneliness and sadness showed significant differences between eating organic foods, self-esteem recovery program, counseling/coaching, and cognitive behavior therapy, while those including shame and guilt showed significant differences between lower body bathing/foot bathing/hot spring bathing, stress-control skills lecture, and observing stars. Emotions including impatience and frustration showed significant differences between pelvic exercise walking, lower body bathing/foot bathing/hot spring bathing, listening to water sounds/hand and foot soak, eating organic foods, cognitive behavior therapy, aroma therapy, camping, and observing stars, while those including anger and sensitivity showed significant differences between pelvic exercise walking, lower body bathing/foot bathing/hot spring bath- ing, making foods, and self-esteem recovery program. The programs that were repeatedly mentioned in the results of differences in the preference of subfertile women for forest therapy programs depending on their emotional characteristics include self-esteem recovery program, half bathing/foot bathing/hot spring bathing and cognitive behavior therapy, which indicates that they tend to prefer mental health-focused programs. The results of this study are expected to be utilized as basic data in developing forest therapy programs for subfertile women who experience emotional difficulties from subfertility. There is still a limitation in this study. Since this study was conducted on about 200 subfertile women using a questionnaire survey, it is difficult to generalize the results of this study. To address this limitation, it will be necessary to provide forest therapy programs for more subfertile women, to analyze their experience and to develop more effective forest therapy programs for subfertile women based on the results.

\section{References}

Adevi, A.A. and P. Grahn. 2011. Attachment to certain natural environments: A basis for choice of recreational settings, activities and restoration from stress? Environ. Nat. Resour. Res. 1(1):36-52. https://doi.org/10.5539/e nrr.v1n1p36

Alvarsson, J.J., S. Wiens, and M.E. Nilsson. 2010. Stress recovery during exposure to nature sound and environmental noise. Int. J. Environ. Res. Public Health 7(3): 1036-1046. https://doi.org/10.3390/ijerph7031036

An, K.W., L.H. Yoo, and J.H. Lee. 2010. Forest recreation. In: Invitation to the forest (pp. 1-37). Daejeon, Korea: Korea Forest Service, Korean Society of Forest Science.

Domar, A.D., P.C. Zuttermeister, and R. Friedman. 1993. The psychological impact of Infertility: A comparison with patients with other medical conditions. J. Psychosom. Obstet. Gynaecol. 14(Suppl):45-52.

Ebbesen, S.M., R. Zachariae, M.Y. Mehlsen, D. Thomsen, A. Højaard, L. Ottosen, T. Petersen, and H.J. Ingerslev. 2009. Stressful life events are associated with a poor in-vitro fertilization (IVF) outcome: A prospective study. Hum. Reprod. 24(9):2173-2182. https://doi.org/ 


\subsection{3/humrep/dep185}

Frijda, N.H. 1986. The emotions. Studies in emotion and social interaction. New York, NY: Cambridge University Press.

Frumkin, H. 2001. Beyond toxicity: Human health and the natural environment. Am. J. Prev. Med. 20(3):234-240.

Gonzalez, M.T., T. Hartig, G.G. Patil, E.W. Martinsen, and M. Kirkevold. 2009. Therapeutic horticulture in clinical depression: A prospective study. Res. Theory Nurs. Pract. 23(4):312-328.

Grahn, P. and U.K. Stigsdotter. 2010. The relation between perceived sensory dimensions of urban green space and stress restoration. Landsc. Urban Plan. 94(3-4):264-275. https://doi.org/10.1016/j.landurbplan.2009.10.012

Greenberg, L.S. 2004. Emotion-focused therapy. Clin. Psychol. Psychother. 11:3-16.

Gullone, E. 2000. The biophilia hypothesis and life in the 21st century: Increasing mental health or increasing pathology J. Happiness Stud. 1(3):293-322. https://doi. org/10.1023/A:1010043827986

Ha, S.Y. 2014. Forest healing program evaluation. In: Forest healing instructor, Level 1 textbook (pp. 369-391). Daejeon, Korea: Korea Forest Service.

Johnsen, S.Å.K. and L.W. Rydstedt. 2013. Active use of the natural environment for emotion regulation. Eur. J. Psychol. 9(4):798-819. https://doi.org/10.5964/ejop.v9i4.633

Kang, E.Y. 2015. Cognitive behavioral therapy for psychosocial adjustment of infertile women. Doctoral dissertation, Myongji University, Seoul, Korea.

Kim, R.Y., W.N. Lee, Y.J. Kim, Y.M. Sung, J.K. Hoh, D.W. Han, Y.M. Choi, and J.H. Hwang. 2011. Current status of infertility counseling in Korea. Korean J. Obstet. Gynecol. 54(10):611-617. https://doi.org/10.5468/KJOG.2011.54.10.611

Kim, Y.H. 2015. The analysis of needs for the development of forest therapy program. Doctoral dissertation, Chungbuk National University, Cheongju, Korea.

Kim, Y.H., D.J. Kim, P.S. Yeoun, and B.J. Choi. 2014a. Preference analysis of general adult on the forest and forest road for the development of forest therapy program. Korean J. Environ. Ecol. 28(5):597-606.
Kim, Y.H., D.J. Kim, P.S. Yeoun, and B.J. Choi. 2014b. The analysis of needs of adults for the development of forest therapy program according to the degree of stress. Proceedings of the conference of Korean Institute of Forest Recreation (pp.39-40). Daejeon, Korea.

Korea Institute for Health and Social Affairs. 2011. Physical, psychological, and socioeconomic burdens of infertility women and demand (Health welfare issue \& focus 74). Sejong, Korea: Author.

Korea Institute for Health and Social Affairs. 2015. The operation status of the counseling program of major developed countries (Research report 2015-03). Sejong, Korea: Author.

Lee, S.H. 2007. The effects of the index of greenness simulation based on restorative environment model upon emotion improvement. Korean J. Health Psychol. 12(2):439-465. https://doi.org/10.17315/kjhp.2007.12.2.009

Lee, S.L. 2019, April 16. Lets start free infertility medical services. Pressian News. Retrieved from www.pressia n.com $/$ news/article?no $=236818$

Lottrup, L., P. Grahn, and U.K. Stigsdotter. 2013. Workplace greenery and perceived level of stress: Benefits of access to a green outdoor environment at the workplace. Landsc. Urban Plan. 110:5-11. https://d oi.org/10.1016/j.landurbplan.2012.09.002

Ministry of Health and Welfare. 2016. Research on the status of infertility counseling and provision of counseling services (Report No. 11-1352000-001853-01). Seoul, Korea: Author.

Mitchell, R. and F. Popham. 2008. Effect of exposure to natural environment on health in equalities: An observational population study. Lancet 372(9650):1655-1660. https://doi.org/10.1016/S0140-6736(08)61689-X

Mother and Child Health Act. 2016. (MOHW) No. 14323 (Korea). Retrieved from http://www.law.go.kr

Park, S.H. 2018. Needs analysis for the development of forest therapy program utilizing the urban forest: Focused on the visitors of Incheon Grand Park. J. Korean Inst. For. Recreat. 22(1):11-24.

Simaika, J.P. and M.J. Samways. 2010. Biophilia as a universal ethic for conserving biodiversity. Conserv. Biol. 24(3):903-906. https://doi.org/10.1111/j.1523-17 
39.2010.01485.x

Sung, J., J.M. Woo, W. Kim, S.K. Lim, and E.J. Chung. 2012. The effect of cognitive behavior therapy-based "forest therapy" program on blood pressure, salivary cortisol level and quality of life in elderly hypertensive patients. Clin. Exp. Hypertens. 34(1):1-7. https://do- i.org/10.3109/10641963.2011.618195

Ulrich, R.S. 1983. Aesthetic and affective response to natural environment. In: I. Altman \& J.F. Wohlwill (Eds.), Behavior and the natural environment (pp. 85-125). Boston, MA: Springer. 